\title{
LYAPUNOV INEQUALITY FOR FRACTIONAL DIFFERENTIAL EQUATIONS WITH PRABHAKAR DERIVATIVE
}

\author{
Shiva Eshaghi AND AlireZA ANSARI
}

\begin{abstract}
In this paper, we consider a fractional boundary value problem including the Prabhakar fractional derivative. We obtain associated Green function for this fractional boundary value problem and get a Lyapunov-type inequality for it.
\end{abstract}

Mathematics subject classification (2010): 26D10, 33E12, 34A08.

Keywords and phrases: Lyapunov inequality, Prabhakar derivative, Mittag-Leffler function, Laplace transform, Riemann-Liouville fractional derivative.

\section{REFERENCES}

[1] L. C. Andrews And B. K. Shivamoggi, Integral Transforms for Engineers, Macmillan Publishing Company, New York, 1988.

[2] M.z Andric, J.z PeCARIC And I.z Peric, A multiple Opial type inequality for the RiemannLiouville fractional derivatives, Journal of mathematical inequalities, 7 (1) (2013), 139-150.

[3] M. Andric, J. PeCARIC AND I. Peric, Composition identities for the Caputo fractional derivatives and applications to Opial-type inequalities, Mathematical Inequalities \& Applications, 16 (3) (2013), 657-670.

[4] B. C. Dhage, Differential inequalities for hybrid fractional differential equations, Journal of mathematical inequalities, 7 (3) (2013), 453-459.

[5] A. Erdélyi, W. Magnus, F. Oberhettinger and F. G. Tricomi, Higher Transcendental Functions, McGraw-Hill, New York-Toronto-London, 1953.

[6] R. A. C. FERREIRA, A Lyapunove-type inequality for a fractional boundary value problem, Fractional Calculus and Applied Analysis, 16 (4) (2013), 978-984.

[7] R. A. C. FERREIRA, On a Lyapunove-type inequality and the zeros of a certain Mittag-Leffler function, Journal of Mathematics Analysis and Applications, 412 (2014), 1058-1063.

[8] K. M. Furati AND N. E. TATAR, Inequalities for fractional differential equations, Mathematical Inequalities \& Applications, 12 (2) (2009), 279-293.

[9] R. Garra, R. Gorenflo, F. Polito And Z. Tomovs Ki, Hilfer-Prabhakar derivatives and some applications, Applied Mathematics and Computation, 242 (2014), 576-589.

[10] R. Gorenflo AND F. MAINARDI, Fractional calculus: integral and differential equations of fractional order, in: A. Carpinteri, F. Mainardi (Eds.), Fractals and Fractional Calculus in Continuum Mechanics, Springer Series on CSM Courses and Lectures, Springer-Verlag, Wien, 378 (1997), 223276.

[11] R. Gorenflo, F. Mainardi And H. M. Srivastava, Special functions in fractional relaxationoscillation and fractional diffusion-wave phenomena, in: D. Bainov (Ed.), Proceedings of the Eighth International Colloquium on Differential Equations, (Plovdiv, Bulgaria; August 18-23, 1997), VSP Publishers, Utrecht and Tokyo, (1998), 195-202.

[12] R. Gorenflo, A. A. Kilbas And S. V. Rogosin, On the generalized Mittag-Leffler type function, Integral Transforms and Special Function, 7 (1998), 215-224.

[13] R. Hilfer And H. Seybold, Computation of the generalized Mittag-Leffler function and its inverse in the complex plane, Integral Transform and Special Function, 17 (2006), 637-652. 
[14] S. IQBAL, K. KRULIC AND J. PECARIC, On an inequality for convex functions with some applications on fractional derivatives and fractional integrals, Journal of mathematical inequalities, 5 (2) (2011), 427-443.

[15] M. JLELI AND B. SAMET, Lyapunov-type inequalities for a fractional differential equation with mixed boundary conditions, Mathematical Inequalities \& Applications, 18 (2) (2015), 443-451.

[16] M. JLELI AND B. SAMET, Lyapunov-type inequalities for fractional boundary-value problems, Electronic Journal of Differential Equation, 201588 (2015), 1-11.

[17] A. A. Kilbas AND M. SAIGO, On Mittag-Leffler type function, fractional calculus operators and solutions of integral equations, Integral Transform and Special Function, 4 (1996), 355-370.

[18] A. A. Kilbas, M. SAIGo And R. K. SaXena, Generalized Mittag-Leffler function and generalized fractional calculus operators, Integral Transforms and Special Function, 15 (2004), 31-49.

[19] A. A. Kilbas, H. M. Srivastava and J. J. Trujillo, Theory and Applications of Fractional Differential Equations, North-Holland Mathematical Studies, 204, Elsevier (North-Holland) Science Publishers, Amsterdam, 2006.

[20] A. M. LyAPUnOv, Probleme général de la stabilité du mouvement, (French Transl. of a Russian paper dated 1893), Ann. Fac. Sci. Univ. Toulouse 2 (1907), 27-247; Reprinted in: Ann. Math. Studies, No. 17, Princeton (1947).

[21] F. MaInARDi, Fractional Calculus and Waves in Linear Viscoelasticity, London: Imperial College Press, 2010.

[22] G. M. MitTaG-Leffler, Sur la nouvelle fonction Eax, Comptes Rendus de l'Académie des Sciences, Paris, 137 (1903), 554-558.

[23] G. M. MitTAG-LEFFLER, Sur la representation analytiqie d'une fonction monogene (cinquieme note), Acta Mathematica, 29 (1905), 101-181.

[24] H. Noroozi, A. Ansari And M. S. Dahaghin, Fundamental inequalities for fractional hybrid differential equations of distributed order and applications, Journal of mathematical inequalities, 8 (3) (2014), 427-443.

[25] T. R. PRABHAKAR, A singular integral equation with a generalized Mittag-Leffler function in the kernel, Yokohama Journal of Mathematics, 19 (1971), 7-15.

[26] H. J. SEYBOLd AND R. HiLfER, Numerical results for the generalized Mittag-Leffler function, Fractional Calculus and Applied Analysis, 8 (2005), 127-139.

[27] H. M. SRIVASTAVA AND Z. TOMOVSKI, Fractional calculus with an integral operator containing a generalized Mittag-Leffler function in the kernel, Applied Mathematics and Computation, 211 (2009), $198-210$.

[28] Z. Tomovski, R. Hilfer AND H. M. SRIVAStaVA, Fractional and operational calculus with generalized fractional derivative operators and Mittag-Leffler type functions, 21 (11) (2010), 797-814.

[29] B. ZHENG, New generalized 2D nonlinear inequalities and applications in fractional differentialintegral equations, Journal of mathematical inequalities, 9 (1) (2015), 235-246.

[30] B. Zheng, Some new discrete fractional inequalities and their applications in fractional difference equations, Journal of mathematical inequalities, 9 (3) (2015), 823-839. 